\title{
Eficácia de herbicidas na dessecação de nabiça e sua ação na germinação de sementes
}

\section{Effect of herbicides on wild radish and seed germination}

\author{
Hermeson dos Santos Vitorino ${ }^{1 *}$; Caio Ferraz de Campos ${ }^{2}$; Dagoberto Martins ${ }^{3}$
}

\begin{abstract}
Resumo
O estudo foi realizado com o objetivo de avaliar a eficácia de herbicidas na dessecação de Raphanus raphanistrum (nabiça) em diferentes épocas de aplicação e sua ação sobre a germinação das sementes dessa planta daninha. O delineamento experimental utilizado foi o de blocos ao acaso, com três repetições. Os herbicidas utilizados foram: glyphosate (360, 720 e $\left.1.080 \mathrm{~g} \mathrm{ha}^{-1}\right), 2,4-\mathrm{D}\left(335,670\right.$ e $\left.1.005 \mathrm{~g} \mathrm{ha}^{-1}\right)$, glyphosate + 2,4-D $\left(360+335,720+670\right.$ e $\left.1.080+1.005 \mathrm{~g} \mathrm{ha}^{-1}\right)$. A pulverização foi realizada em três épocas diferentes: $1^{\mathrm{a}}$ época (pleno florescimento) - 62 dias após a emergência (DAE), $2^{\mathrm{a}}$ época (início da formação de vagens) - 92 DAE e $3^{a}$ época (final da formação de vagens) - 108 DAE. Aos 14, 21, 28, 35 e 42 dias após a aplicação (DAA), foi avaliada a dessecação visualmente e, aos 42 DAA a massa seca da parte aérea e as sementes da $2^{\mathrm{a}}$ e $3^{\mathrm{a}}$ épocas foram coletadas para a realização do teste de germinação. Todos os tratamentos químicos testados foram eficientes no controle das plantas de nabiça nas $1^{\mathrm{a}}$ e $2^{\mathrm{a}}$

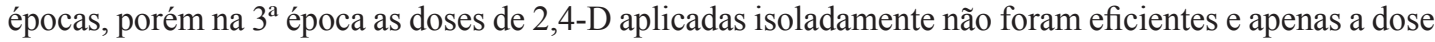
maior de glyphosate aplicada de forma isolada ou em mistura proporcionou um controle total das plantas. Percentualmente, a redução da massa seca de plantas foi maior com a aplicação das doses maiores dos tratamentos químicos. A aplicação dos herbicidas afetou o processo germinativo das sementes de nabiça, sendo o herbicida 2,4-D proporcionou maior redução na germinação da $2^{\mathrm{a}} \mathrm{e} 3^{\mathrm{a}}$ épocas.
\end{abstract}

Palavras-chave: Controle químico, plantio direto, glyphosate, 2,4-D

\begin{abstract}
The study was conducted to evaluate the efficacy of herbicides in desiccation Raphanus raphanistrum (wild radish) in different application times and their effects on weed seed germination. The experimental had a randomized block design with three replications. The herbicides used were: glyphosate $(360 ; 720$; and $\left.1080 \mathrm{~g} \mathrm{ha}^{-1}\right), 2,4-\mathrm{D}\left(335 ; 670\right.$; and $\left.1005 \mathrm{~g} \mathrm{ha}^{-1}\right)$, glyphosate + 2,4-D $(360+335 ; 720+670$; and 1080 $\left.+1005 \mathrm{~g} \mathrm{ha}^{-1}\right)$. Spraying was conducted at three different times: 1 st season (full bloom) - at 62 days after emergence (DAE), 2nd season (beginning of pod formation) - at $92 \mathrm{DAE}$ and 3rd season (end of pod formation) - at 108 DAE. At 14, 21, 28, 35, and 42 days after application (DAA), the desiccation was evaluated visually, and 42 DAA dry mass of shoots and seeds of the 2nd and 3rd times were collected for the test of germination. All chemical treatments tested were effective in controlling the plants of wild radish in the 1st and 2nd times, but in the 3rd time doses of 2,4-D applied singly were not effective and only the highest dose of glyphosate applied singly or in mixture provided a total plant control. In terms of percentage, the reduction in dry matter of plants was higher with the application of larger doses of chemical treatments. The herbicides affected the germination of seeds of wild radish, and the herbicide 2,4-D provided greater reduction in germination in the $2 \mathrm{nd}$ and $3 \mathrm{rd}$ seasons.
\end{abstract}

Key words: Chemical control, no-tillage, glyphosate, 2,4-D

${ }^{1}$ Prof. Dr. da Universidade Estadual do Piauí, UESPI, Picos, PI. E-mail: vitorinohermeson@gmail.com

2 R\&D na Dow AgroSciences, Rondonópolis, MT. E-mail: caio.agro@hotmail.com

${ }^{3}$ Prof. Dr. do Dept ${ }^{\circ}$ de Agricultura, Universidade Estadual Paulista "Júlio Mesquita Filho", UNESP, Botucatu, SP. E-mail: dmartins@fca.unesp.br

* Autor para correspondência 


\section{Introdução}

As plantas daninhas são importantes por prejudicarem diretamente a produção das culturas agrícolas, provocando, também, aumento do custo de produção pelos investimentos necessários em seu manejo. Devido a sua rusticidade podem germinar, desenvolver-se e reproduzir-se em condições ambientais pouco favoráveis, tais como em estresse hídrico, umidade excessiva, temperaturas inadequadas, fertilidade desfavorável, elevada salinidade, acidez ou alcalinidade (PITELLI, 1985). Neste contexto, o conhecimento do desenvolvimento e fenologia das principais espécies de plantas daninhas é de fundamental importância para o manejo da sua infestação nas culturas, uma vez que o controle ineficiente aumenta a distribuição destas plantas na maioria dos sistemas de cultivo (EMBRAPA, 2001).

O manejo inicial das plantas daninhas no sistema de plantio direto é geralmente com a aplicação de herbicidas dessecantes com ação em torno de dez dias antes da semeadura. No entanto, neste sistema podem ocorrer problemas, como rebrotas e emergência de um novo fluxo proveniente do banco de sementes do solo, o que pode interferir no estabelecimento, desenvolvimento inicial e rendimento final da cultura, devido à vantagem competitiva no estabelecimento anterior das plantas daninhas.

Uma alternativa bastante utilizada é a aplicação de herbicida sistêmico, normalmente glyphosate, imediatamente antes da semeadura, em operação rotineiramente chamada de "Aplique-Plante" (APP) (OLIVEIRA JÚNIOR et al., 2006). Até o registro do glyphosate no início dos anos 80 , para o plantio direto existiam apenas os herbicidas paraquat e 2,4-D (2,4D Éster e 2,4-D amina) registrados para a dessecação em pré-plantio. Embora sistêmico, o 2,4-D só afeta as plantas dicotiledôneas e o controle do paraquat sobre as gramíneas apresenta-se efetivo em plantas no estádio de crescimento inicial, pois em plantas adultas pode haver rebrota, dependendo da espécie, o que representa um obstáculo à economicidade do plantio direto na época. A formulação de herbicidas sistêmicos não seletivos, como o glyphosate, tornou esta opção realmente eficiente antes do advento das culturas transgênicas, e iniciou-se uma etapa de aprimoramento do controle das plantas daninhas (LANDERS, 2005).

Raphanus raphanistrum L. (nabiça) é uma espécie invasora pertencente à família Brassicaceae (Cruciferae). No Brasil, ocorre com intensidade na região Sul e em menor escala na região CentroOeste. É uma espécie com grande capacidade de competição pela grande quantidade de sementes viáveis que forma e que tende a infestar de modo intenso as culturas, especialmente de cereais de inverno (LORENZI, 2006). Segundo Young e Cousens (1998), a espécie $R$. raphanistrum tem alto potencial de germinação e apresentam dormência resultante de um tegumento que envolve a semente. Segundo Reeves, Code e Piggin (1981), a dormência aliada à alta reprodução e longevidade das sementes possibilita a formação de um grande banco de sementes no solo, tornando o controle dificultado através das diferentes práticas agrícolas.

O controle desta planta daninha é realizada por herbicidas sistêmicos como glyphosate e 2,4-D, de acordo com Penckowski, Podolan e López-Ovejero (2003), a nabiça pode ser controlada com eficiência usando herbicidas a base de 2,4-D apresentaram controle acima de $90 \%$ aos 30 dias após a aplicação deste herbicida. Diante do exposto, objetivouse avaliar o controle de plantas de nabiça em três épocas distintas e estudar o efeito dos herbicidas sobre a germinação das sementes que vierem a ser formadas desta planta daninha.

\section{Material e Métodos}

O estudo foi instalado e conduzido de abril a setembro de 2011, em uma área experimental pertencente à FCA/UNESP, campus de Botucatu. O solo foi classificado como Nitossolo Vermelho (EMBRAPA, 2006), textura média argilosa, com topografia suavemente ondulada e condições de boa drenagem. 
O delineamento experimental utilizado foi de blocos ao acaso com três repetições, sendo que a unidade experimental foi representada por parcelas com dimensões $(2,0 \times 4,0 \mathrm{~m}$, totalizando área de $8,0 \mathrm{~m}^{2}$ ). A planta daninha utilizada no estudo foi a nabiça, sendo que seu crescimento na área experimental foi espontâneo e apresentou um ciclo de 192 dias. A pulverização dos herbicidas foi realizada em três épocas diferentes: $1^{\mathrm{a}}$ época (pleno florescimento) - 62 dias após a emergência (DAE), $2^{\mathrm{a}}$ época (início da formação de vagens) - 92 DAE as plantas daninhas estavam com 170 vagens planta $^{-1} \mathrm{e}$ $3^{\mathrm{a}}$ época (final da formação de vagens) - 108 DAE, quando as plantas daninhas apresentavam-se com 429 vagens planta ${ }^{-1}$ e encontravam-se na fase final de maturação.

Os tratamentos químicos (Tabela 1) foram aplicados utilizando-se um pulverizador costal, pressurizado a $\mathrm{CO}_{2}$, equipado com um reservatório de 2 litros. O equipamento foi regulado para proporcional um consumo de calda de $200 \mathrm{~L} \mathrm{ha}^{-1}$. A barra de aplicação estava constituída de quatro pontas do tipo jato plano "Teejet" XR 11002 VS, distanciados $50 \mathrm{~cm}$ entre si.

Tabela 1. Tratamentos herbicidas e seus respectivos nomes comerciais utilizados no controle de plantas de Raphanus raphanistrum. Botucatu/SP, 2011.

\begin{tabular}{lccc}
\hline Tratamentos & $\begin{array}{c}\text { Dose } \\
\left(\mathbf{g ~ h a}^{-\mathbf{1}} \mathbf{)}\right.\end{array}$ & Produto Comercial & $\begin{array}{c}\text { Dose } \\
\left(\mathbf{g ~ p . c .} \mathbf{h a}^{-\mathbf{1}} \mathbf{)}\right.\end{array}$ \\
\hline 1. glyphosate & 360 & Roundup WG & 500 \\
2. glyphosate & 720 & Roundup WG & 1.000 \\
3. glyphosate & 1.080 & Roundup WG & 1.500 \\
4. 2,4-D & 335 & DMA 806 BR & 500 \\
$\mathbf{5 . 2 , 4 - D}$ & 670 & DMA 806 BR & 1.000 \\
6. 2,4-D & 1.005 & DMA 806 BR & 1.500 \\
7. gly + 2,4-D & $360+335$ & Roundup WG+ DMA 806 BR & $500+500$ \\
8. gly + 2,4-D & $720+670$ & Roundup WG+ DMA 806 BR & $1.000+1.000$ \\
9. gly + 2,4-D & $1.080+1.005$ & Roundup WG+ DMA 806 BR & $1.500+1.500$ \\
10. testemunha & --- & --- & -- \\
\hline
\end{tabular}

${ }^{1}$ gly - glyphosate.

Fonte: Elaboração dos autores.

As avaliações visuais de dessecação foram realizadas aos 14, 21, 28, 35 e 42 dias após a aplicação (DAA), avaliações estas, realizadas de forma percentual, no qual ' 0 ' significa ausência de sintomas e 100 corresponde à morte da planta, segundo a Sociedade Brasileira da Ciência das Plantas Daninhas - SBCPD (1995). Aos 42 DAA, o material de um metro quadrado foi colhido aos 104 DAE para a $1^{\text {a }}$ época, 134 DAE para a $2^{\mathrm{a}}$ época e para $3^{a}$ época 192 DAE e levado para secar em estufa com circulação forçada de ar a $65^{\circ} \mathrm{C}$, para obtenção da massa seca.

As vagens produzidas foram colhidas aos 42
DAA, em uma área de 4,0 $\mathrm{m}^{2}$ no centro das parcelas experimentais e colocadas para secar a sombra. Após esse período as sementes foram retiradas e colocadas para germinarem em caixas plásticas "gerbox", com papel germitest contendo 2,5 vezes a massa do papel seco de água destilada e em número de 50 sementes (Brasil, 1992). As caixas foram mantidas a uma temperatura de $30^{\circ} \mathrm{C}$ e os resultados expressos em percentagem de plântulas normais.

Os dados foram submetidos a análise da variância, posteriormente foi realizado o teste de Tukey a $5 \%$. Os dados de germinação foram transformados pelo Arcosen $\sqrt{ } \mathrm{x} / 100$. 


\section{Resultados e Discussão}

$\mathrm{O}$ intervalo entre a emergência até as plantas atingirem $50 \%$ do florescimento pleno foi de 62 dias. Nas condições de Pariquera-Açu em São Paulo, Lima et al. (2007) encontraram resultados semelhantes, onde observaram que $50 \%$ do florescimento pleno das plantas de nabiça deram-se 66 dias após a semeadura, quando esta foi realizada em 05 de junho.

$\mathrm{Na}$ primeira época de aplicação (pleno florescimento), o glyphosate controlou eficientemente as plantas de nabiça partir dos 21 DAA, enquanto que para o 2,4-D esse controle ocorreu apenas a partir dos 28 DAA (Tabela 2). Segundo Farinelli, Penarol e Lemos (2005), o controle de nabiça realizado com a dose de $670 \mathrm{~g}$ e.a. $\mathrm{ha}^{-1}$ de 2,4-D, até o florescimento, foi considerado muito bom, acima de $85 \%$, corroborando os dados observados neste estudo. Já, em outro estudo, Bohm et al. (2011) observaram um excelente controle das plantas de nabiça pelo herbicida glyphosate, sendo de $100 \%$ a partir dos 28 DAA.

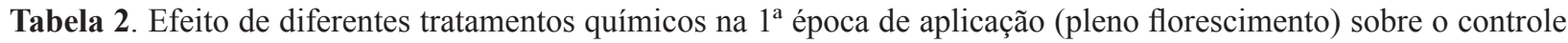
de plantas de Raphanus raphanistrum, em diferentes períodos de avaliação. Botucatu/SP, 2011.

\begin{tabular}{lcccccc}
\hline Tratamentos & $\begin{array}{c}\text { Doses } \\
\mathbf{( g ~ h a}^{-1} \mathbf{)}\end{array}$ & $\mathbf{1 4 D A A}$ & $\mathbf{2 1 D A A}$ & $\begin{array}{c}\text { Controle } \\
\text { 28DAA }\end{array}$ & 35DAA & 42DAA \\
\hline 1. glyphosate & 360 & $73,0 \mathrm{c}$ & $89,3 \mathrm{c}$ & $95,0 \mathrm{bc}$ & $93,3 \mathrm{bc}$ & $93,3 \mathrm{~b}$ \\
2. glyphosate & 720 & $85,3 \mathrm{~b}$ & $96,0 \mathrm{ab}$ & $98,3 \mathrm{ab}$ & $100,0 \mathrm{a}$ & $100,0 \mathrm{a}$ \\
3. glyphosate & 1.080 & $95,0 \mathrm{a}$ & $99,3 \mathrm{a}$ & $100,0 \mathrm{a}$ & $100,0 \mathrm{a}$ & $100,0 \mathrm{a}$ \\
4. 2,4-D & 335 & $44,3 \mathrm{e}$ & $72,6 \mathrm{e}$ & $88,0 \mathrm{~d}$ & $90,3 \mathrm{c}$ & $91,6 \mathrm{~b}$ \\
5. 2,4-D & 670 & $60,0 \mathrm{~d}$ & $79,3 \mathrm{de}$ & $93,0 \mathrm{c}$ & $97,3 \mathrm{ab}$ & $100,0 \mathrm{a}$ \\
6. 2,4-D & 1.005 & $65,3 \mathrm{~cd}$ & $84,3 \mathrm{~cd}$ & $97,3 \mathrm{ab}$ & $100,0 \mathrm{a}$ & $100,0 \mathrm{a}$ \\
7. gly $\mathbf{1}+\mathbf{2 , 4 - D}$ & $360+335$ & $69,3 \mathrm{c}$ & $93,6 \mathrm{ab}$ & $95,7 \mathrm{bc}$ & $95,3 \mathrm{~b}$ & $100,0 \mathrm{a}$ \\
8. gly+2,4-D & $720+670$ & $83,6 \mathrm{~b}$ & $96,0 \mathrm{ab}$ & $99,0 \mathrm{ab}$ & $99,7 \mathrm{a}$ & $100,0 \mathrm{a}$ \\
9. gly+2,4-D & $1.080+1.005$ & $88,7 \mathrm{ab}$ & $97,6 \mathrm{ab}$ & $100,0 \mathrm{a}$ & $100,0 \mathrm{a}$ & $100,0 \mathrm{a}$ \\
\hline CV (\%) & - & 4,09 & 3,31 & 1,55 & 1,52 & 1,11 \\
\hline
\end{tabular}

Médias seguidas de mesma letra na coluna não diferem entre si pelo teste de Tukey ( $>0,05)$.

${ }^{1}$ gly - glyphosate.

DAA - Dias após a aplicação.

Fonte: Elaboração dos autores.

Já para a mistura houve uma redução no controle inicial com relação ao herbicida glyphosate aplicado isoladamente até os 21 DAA, porém essa mistura passou a proporcionar um controle eficiente das plantas a partir dos 28 DAA e, atingiu aos 35 DAA um controle total das plantas, como registrado também quando da aplicação isolada de glyphosate nas duas doses maiores testadas. Agostinetto et al. (2009), trabalharam com a dose de 1.440 g e.a. ha $^{-1}$ de Round-up Ready observaram um controle de $97,3 \%$ aos 28 DAA das plantas de nabiça, o que corrobora os resultados ora encontrados com a aplicação isolada de glyphosate.

Quando os herbicidas foram aplicados na $2^{\mathrm{a}}$ época, ou seja, no inicio da formação de vagens, houve uma redução geral no controle com relação à $1^{\mathrm{a}}$ época, pois o controle eficiente da menor dose de glyphosate ocorreu apenas aos 35 DAA, sendo que o mesmo ocorreu para o herbicida 2,4-D (Tabela 3). 


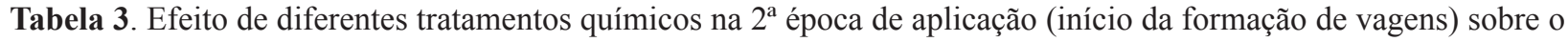
controle de plantas de Raphanus raphanistrum, em diferentes períodos de avaliação. Botucatu/SP, 2011.

\begin{tabular}{|c|c|c|c|c|c|c|}
\hline \multirow{2}{*}{ Tratamentos } & \multirow{2}{*}{$\begin{array}{c}\text { Doses } \\
\left(\mathrm{g} \mathrm{e.a.} \mathrm{ha}^{-1}\right)\end{array}$} & \multicolumn{5}{|c|}{ Controle (\%) } \\
\hline & & 14DAA & 21DAA & 28DAA & 35DAA & 42DAA \\
\hline 1. glyphosate & 360 & $16,0 \mathrm{~d}$ & $41,7 \mathrm{e}$ & $73,7 \mathrm{bc}$ & $92,3 \mathrm{a}$ & $96,6 \mathrm{a}$ \\
\hline 2. glyphosate & 720 & $23,3 \mathrm{bcd}$ & $66,7 \mathrm{bc}$ & 94,7 abc & $100,0 \mathrm{a}$ & $100,0 \mathrm{a}$ \\
\hline 3. glyphosate & 1.080 & $30,3 \mathrm{~b}$ & $82,7 \mathrm{ab}$ & $97,7 \mathrm{ab}$ & $100,0 \mathrm{a}$ & $100,0 \mathrm{a}$ \\
\hline 4. $2,4-\mathrm{D}$ & 335 & $16,0 \mathrm{~d}$ & $44,7 \mathrm{de}$ & $75,0 \mathrm{bc}$ & $90,0 \mathrm{a}$ & $96,6 \mathrm{a}$ \\
\hline 5. 2,4-D & 670 & $19,3 \mathrm{~cd}$ & 52,0 cde & $76,0 \mathrm{abc}$ & $91,7 \mathrm{a}$ & $95,0 \mathrm{a}$ \\
\hline 6. 2,4-D & 1.005 & $25,3 \mathrm{bc}$ & 52,7 cde & $77,7 \mathrm{abc}$ & $93,3 \mathrm{a}$ & $97,0 \mathrm{a}$ \\
\hline 7. gly $^{1}+2,4-D$ & $360+335$ & $21,0 \mathrm{~cd}$ & $60,0 \mathrm{~cd}$ & $71,7 \mathrm{c}$ & $93,3 \mathrm{a}$ & $98,7 \mathrm{a}$ \\
\hline 8. gly+2,4-D & $720+670$ & $31,0 \mathrm{~b}$ & $77,6 \mathrm{ab}$ & $85,7 \mathrm{abc}$ & $100,0 \mathrm{a}$ & $100,0 \mathrm{a}$ \\
\hline 9. gly $+2,4-D$ & $1.080+1.005$ & $41,0 \mathrm{a}$ & $92,3 \mathrm{a}$ & $100,0 \mathrm{a}$ & $100,0 \mathrm{a}$ & $100,0 \mathrm{a}$ \\
\hline $\mathrm{CV}(\%)$ & - & 12,11 & 9,38 & 10,36 & 4,25 & 2,38 \\
\hline
\end{tabular}

Médias seguidas de mesma letra na coluna não diferem entre si pelo teste de Tukey $(p>0,05)$.

${ }^{1}$ gly - glyphosate.

DAA - Dias após a aplicação.

Fonte: Elaboração dos autores.

O herbicida 2,4-D proporcionou um controle final excelente para todas as doses testadas, o que sugere um controle de $R$. raphanistrum realizado no início da formação de vagens pode ainda vantajoso e eficiente. Segundo Rodrigues e Almeida (1998), o 2,4-D é uma auxina sintética que atua provocando distúrbios (crescimento anormal de tecidos, obstrução do floema, morte do sistema radicular, epinastia das folhas), as quais levam a morte de plantas com pontos de crescimento ativos.

As misturas proporcionaram na $2^{\text {a }}$ época um controle satisfatório mesmo nas menores doses utilizadas, ao final das avaliações, sendo que em algumas situações ocorreu antecipação dos sintomas de fitotoxicidade quando comparado às doses isoladas, contudo, aos $21 \mathrm{DAA}$, a maior dose desta mistura já proporcionava um controle de 92,3\%. Já, todos os tratamentos em associação dos herbicidas controlaram de forma eficiente as plantas daninhas de $R$. raphanistrum ao final das avaliações.

$\mathrm{Na} 3^{\mathrm{a}}$ época, período esse em que as plantas daninhas apresentavam-se no final da formação de vagens, o controle dessas plantas foi satisfatório apenas quando da aplicação isolada do herbicida glyphosate nas doses de 720 e 1.080 g. ha ${ }^{-1}$ e da mistura de glyphosate $+2,4-\mathrm{D}$ nas maiores doses $720+670$ g. ha-1 e $1.080+1.005$ g. ha' (Tabela 4).

O herbicida glyphosate nas doses de 360 e 720 $\mathrm{g}$ ha $^{-1}$ proporcionaram um controle bom aos 21 DAA, porém ocorreu um decréscimo no controle ao final das avaliações, aos $42 \mathrm{DAA}$, no qual para a menor dose esse controle pode ser considerado insatisfatório.

O 2,4-D mostrou-se ineficiente no controle das plantas daninhas, independente das doses testadas. Em concentrações elevadas, o 2,4-D inibe o crescimento e a divisão celular, geralmente nas regiões meristemáticas, as quais acumulam tanto assimilados provenientes da fotossíntese quanto o herbicida translocado pelo floema (OLIVEIRA JÚNIOR, 2011), o que poderia explicar o controle insatisfatório das plantas de $R$. raphanistrum na $3^{\mathrm{a}}$ época de aplicação, fato este que se justifica pelas plantas daninhas estarem no estádio final do ciclo de desenvolvimento. No entanto, quando em mistura com o glyphosate $(720+670$ e 1.080 $\left.+1.005 \mathrm{~g} \mathrm{ha}^{-1}\right)$ proporcionou controles eficientes, com destaque para maior dose. 
Tabela 4. Efeito de diferentes tratamentos químicos na $3^{\mathrm{a}}$ época de aplicação (final da formação de vagens) sobre o controle de plantas de Raphanus raphanistrum, em diferentes períodos de avaliação. Botucatu/SP, 2011.

\begin{tabular}{lcccccc}
\hline Tratamentos & $\begin{array}{c}\text { Doses } \\
\mathbf{( g ~ h a - 1 ~}^{-1}\end{array}$ & 14DAA & 21DAA & $\begin{array}{c}\text { Controle (\%) } \\
\text { 28DAA }\end{array}$ & 35DAA & 42DAA \\
\hline 1. glyphosate & 360 & $48,3 \mathrm{bc}$ & $89,7 \mathrm{ab}$ & $81,0 \mathrm{abc}$ & $78,7 \mathrm{bc}$ & $76,0 \mathrm{bcd}$ \\
2. glyphosate & 720 & $57,7 \mathrm{~b}$ & $98,0 \mathrm{a}$ & $88,0 \mathrm{ab}$ & $84,7 \mathrm{ab}$ & $82,0 \mathrm{abc}$ \\
3. glyphosate & 1.080 & $91,7 \mathrm{a}$ & $100,0 \mathrm{a}$ & $100,0 \mathrm{a}$ & $100,0 \mathrm{a}$ & $100,0 \mathrm{a}$ \\
4. 2,4-D & 335 & $49,0 \mathrm{~b}$ & $89,3 \mathrm{ab}$ & $79,3 \mathrm{abc}$ & $76,0 \mathrm{bc}$ & $73,3 \mathrm{bcd}$ \\
5. 2,4-D & 670 & $21,7 \mathrm{~d}$ & $65,0 \mathrm{c}$ & $55,0 \mathrm{~d}$ & $58,3 \mathrm{c}$ & $57,0 \mathrm{~d}$ \\
6. 2,4-D & 1.005 & $22,7 \mathrm{~cd}$ & $71,7 \mathrm{bc}$ & $61,7 \mathrm{~cd}$ & $62,3 \mathrm{c}$ & $62,3 \mathrm{~cd}$ \\
7. gly $\mathbf{1}+\mathbf{2 , 4 - D}$ & $360+335$ & $31,7 \mathrm{bcd}$ & $85,0 \mathrm{ab}$ & $75,0 \mathrm{bcd}$ & $72,0 \mathrm{bc}$ & $69,0 \mathrm{bcd}$ \\
8. gly+2,4-D & $720+670$ & $47,3 \mathrm{bcd}$ & $96,0 \mathrm{a}$ & $89,3 \mathrm{ab}$ & $87,3 \mathrm{ab}$ & $85,0 \mathrm{ab}$ \\
9. gly+2,4-D & $1.080+1.005$ & $90,0 \mathrm{a}$ & $100,0 \mathrm{a}$ & $100,0 \mathrm{a}$ & $100,0 \mathrm{a}$ & $100,0 \mathrm{a}$ \\
\hline CV (\%) & - & 17,79 & 7,70 & 9,38 & 9,01 & 9,62 \\
\hline
\end{tabular}

Médias seguidas de mesma letra na coluna não diferem entre si pelo teste de Tukey ( $>00,05)$.

${ }^{1}$ gly - glyphosate.

DAA - Dias após a aplicação.

Fonte: Elaboração dos autores.

Em relação ao acúmulo de massa seca, notase na $1^{\text {a }}$ época avaliada que a aplicação isolada de glyphosate, independente da dose testada, foi efetiva na redução da massa seca das plantas e também mais eficiente que a utilização de sua mistura com 2,4-D dependendo da dose observada.

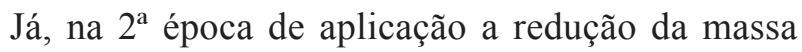
seca de plantas foi menos intensa com a aplicação isolada da menor dose de glyphosate testada e na $3^{\text {a }}$ época apenas a dose maior de glyphosate determinou reduções significativas no acúmulo de massa seca de plantas, o que evidencia o efeito do estádio de crescimento das plantas sobre a ação do herbicida. Destaca-se, em relação às misturas, que apenas as doses maiores dos dois herbicidas testados foram efetivas de forma simultânea em todas as épocas de aplicação (Tabela 5).

Tabela 5. Efeito de diferentes tratamentos químicos sobre a massa seca de plantas de Raphanus raphanistrum em três épocas de aplicação. Botucatu/SP, 2011.

\begin{tabular}{lcccc}
\hline Tratamentos & $\begin{array}{c}\text { Doses } \\
\mathbf{g ~ h a}^{-1} \mathbf{)}\end{array}$ & $\mathbf{1}^{\mathbf{a}}$ Época & $\begin{array}{c}\text { Massa Seca (\%) } \\
\mathbf{2}^{\mathbf{a}} \text { Época }\end{array}$ & $\mathbf{3}^{\mathbf{a}}$ É poca \\
\hline 1. glyphosate & 360 & $53,4 \mathrm{bc}$ & $79,4 \mathrm{ab}$ & $111,3 \mathrm{a}$ \\
2. glyphosate & 720 & $44,4 \mathrm{bc}$ & $54,4 \mathrm{~b}$ & $87,7 \mathrm{ab}$ \\
3. glyphosate & 1.080 & $34,1 \mathrm{c}$ & $47,8 \mathrm{~b}$ & $74,4 \mathrm{~b}$ \\
4. 2,4-D & 335 & $64,9 \mathrm{abc}$ & $65,5 \mathrm{ab}$ & $74,9 \mathrm{~b}$ \\
$\mathbf{5 . ~ 2 , 4 - D}$ & 670 & $65,2 \mathrm{abc}$ & $71,1 \mathrm{ab}$ & $77,4 \mathrm{~b}$ \\
6. 2,4-D & 1.005 & $55,6 \mathrm{bc}$ & $58,9 \mathrm{ab}$ & $72,8 \mathrm{~b}$ \\
7. gly $\mathbf{1}+\mathbf{2 , 4 - D}$ & $360+335$ & $83,6 \mathrm{ab}$ & $73,3 \mathrm{ab}$ & $83,1 \mathrm{ab}$ \\
$\mathbf{8 . ~ g l y + 2 , 4 - D}$ & $720+670$ & $79,1 \mathrm{bc}$ & $78,9 \mathrm{ab}$ & $82,3 \mathrm{ab}$ \\
9. gly+2,4-D & $1.080+1.005$ & $49,9 \mathrm{bc}$ & $50,6 \mathrm{~b}$ & $72,8 \mathrm{~b}$ \\
$\mathbf{1 0 .}$ Testemunha & - & $100,0 \mathrm{a}$ & $100,0 \mathrm{a}$ & $100,0 \mathrm{a}$ \\
\hline CV (\%) & - & 22,1 & 21,7 & 11,9 \\
\hline
\end{tabular}

Médias seguidas de mesma letra na coluna não diferem entre si pelo teste de Tukey ( $>0,05)$.

${ }^{1}$ gly - glyphosate.

DAA - Dias após a aplicação.

Fonte: Elaboração dos autores. 
Ressalta-se que a aplicação isolada de 2,4-D foi efetiva na redução da massa seca de plantas na $1^{\text {a }}$ época de aplicação apenas na maior dose testada (1.005 $\left.\mathrm{g} \mathrm{ha}^{-1}\right)$, na $2^{\mathrm{a}}$ época os efeitos não foram satisfatórios e na $3^{\text {a }}$ época de aplicação todas as doses foram eficazes, demonstrando haver efeito do estádio de desenvolvimento sobre a eficácia de herbicidas (Tabela 5).

$\mathrm{Na} 3^{\mathrm{a}}$ época houve acúmulo maior de massa seca quando da aplicação da dose menor de glyphosate do que o observado na testemunha, o que sugere um efeito benéfico da aplicação deste herbicida. Vários pesquisadores sugerem que subdoses de glyphosate podem trazer estímulos ao crescimento vegetal, efeito este conhecido como hormético (WAGNER; KOGAN, 2003; GODOY, 2007; CARBONARI; MESCHEDE; VELINE, 2007). Velini et al., (2008) observaram estímulos de crescimento da parte aérea de soja, eucalipto, milho, pinus, café e citrus, quando se testou a aplicação de baixas dosagens de glyphosate simulando deriva. Provavelmente essa é a causa do maior crescimento a nabiça na menor dose de glyphosate que pode ter ocorrido também no caso ora estudado um efeito hormético nas plantas de nabiça proporcionado pela menor dose utilizada do herbicida glyphosate.

O total de massa seca reduzida após a aplicação na $3^{\text {a }}$ época para todos os tratamentos químicos estudados não foi expressiva, provavelmente isto ocorreu pelo grande acúmulo de massa seca nos frutos devido à drenagem de nutriente já ocorrida neste período para a formação das sementes.

A germinação das sementes colhidas na $2^{\mathrm{a}} \mathrm{e}$ $3^{\text {a }}$ épocas foi avaliada para todos os tratamentos (Tabela 6), considerando a testemunha como $100,0 \%$ de germinação. Na primeira época de aplicação dos herbicidas as plantas de nabiça não produziram sementes, pois os herbicidas testados proporcionaram a morte das plantas antes da formação de vagens (Tabela 2). A germinação das sementes de $R$. raphanistrum na testemunha nas duas épocas avaliadas foram bem distintas, o que sugere uma maturação desuniforme das sementes colhidas.

Tabela 6. Efeito de diferentes tratamentos químicos sobre a germinação de sementes Raphanus raphanistrum em duas épocas de aplicação. Botucatu/SP, 2011.

\begin{tabular}{|c|c|c|c|c|}
\hline \multirow{2}{*}{ Tratamentos } & \multirow{2}{*}{$\begin{array}{c}\text { Doses } \\
\left(\mathrm{g} \mathrm{ha}^{-1}\right)\end{array}$} & \multicolumn{3}{|c|}{ Germinação (\%) ${ }^{2}$} \\
\hline & & $1^{\text {a }}$ Época $^{3}$ & $2^{\text {a }}$ Época & $3^{\text {a }}$ Época \\
\hline 1. glyphosate & 360 & - & $61,1 \mathrm{bc}$ & $78,3 \mathrm{ab}$ \\
\hline 2. glyphosate & 720 & - & $77,1 \mathrm{ab}$ & $57,7 \mathrm{abc}$ \\
\hline 3. glyphosate & 1.080 & - & $39,7 \mathrm{bcd}$ & $42,3 \mathrm{bc}$ \\
\hline 4. 2,4-D & 335 & - & $52,7 \mathrm{bcd}$ & $77,3 \mathrm{ab}$ \\
\hline 5. 2,4-D & 670 & - & $36,6 \mathrm{~cd}$ & $23,7 \mathrm{c}$ \\
\hline 6. 2,4-D & 1.005 & - & $22,1 \mathrm{~d}$ & $38,1 \mathrm{bc}$ \\
\hline 7. gly $^{1}+2,4-D$ & $360+335$ & - & $42,7 \mathrm{bcd}$ & $28,9 \mathrm{c}$ \\
\hline 8. gly+2,4-D & $720+670$ & - & $29,4 \mathrm{~cd}$ & $53,6 \mathrm{bc}$ \\
\hline 9. gly+2,4-D & $1.080+1.005$ & - & $37,3 \mathrm{~cd}$ & $52,8 \mathrm{bc}$ \\
\hline 10. Testemunha & - & - & $100,0 \mathrm{a}$ & $100,0 \mathrm{a}$ \\
\hline CV (\%) & - & - & 17,87 & 18,02 \\
\hline
\end{tabular}

Médias seguidas de mesma letra na coluna não diferem entre si pelo teste de Tukey $(\mathrm{p}>0,05)$.

DAA - Dias após a aplicação.

${ }^{1}$ gly - glyphosate.

${ }^{2}$ Dados transformados (Arcosen $\left.\sqrt{ } \mathrm{x} / 100\right)$.

${ }^{3}$ Período em que as plantas não produziram sementes (durante o florescimento).

Fonte: Elaboração dos autores. 
De acordo com Oliveira Júnior e Constantin (2001) as plantas daninhas possuem uma desuniformidade no processo germinativo, pois se as plantas daninhas concentrassem sua germinação num mesmo período, o controle seria facilitado, portanto, dessa forma, essas espécies se valem de artifícios como dormência e imaturidade de embrião que lhes conferem desuniformidade, possibilitando a perpetuação da espécie.

A aplicação de glyphosate na $2^{\mathrm{a}}$ época proporcionou redução na germinação das sementes de nabiça, exceto para a segunda dose testada do herbicida (720 $\left.\mathrm{g} \mathrm{ha}^{-1}\right)$. Exemplos do efeito da ação do herbicida glyphosate sobre a germinação de espécies de plantas daninhas são escassos na literatura, mas de acordo com Melhorança Filho, Pereira e Martins (2011), o glyphosate quando aplicado em subdose pode proporcionar redução da germinação de sementes de diversas espécies cultivadas, como a soja.

Já em todas as doses do herbicida 2,4-D utilizadas obsevou-se efeito negativo sobre a germinação das sementes de R. raphanistrum, sendo que a maior dose de 2,4-D testada proporcionou uma redução de 78,0\% na percentagem de germinação. Segundo Cassanego, Droste e Windischi (2010) sementes de Regnellidium diphyllum sobre o efeito de doses concentradas de 2,4-D, entre 9,6 e 19,2 $\mathrm{mg} \mathrm{L}^{-1}$, apresentaram efeitos na germinação dessas sementes quando embebidas pela solução deste herbicida. Ressalta-se que, a aplicação da mistura de glyphosate $+2,4$-D proporcionou uma germinação semelhante a aplicação isolada de 2,4-D, enquanto que o glyphosate, aplicado nas doses de 360 e 720 g e.a. ha ${ }^{-1}$, determinou uma menor redução da germinação em relação à mistura nas doses $720+$ 670 e $1.080+1.005 \mathrm{~g} \mathrm{ha}^{-1}$.

$\mathrm{Na} 3^{\mathrm{a}}$ época de aplicação dos tratamentos, a testemunha apresentou uma menor germinação em comparação à segunda época, o que pode estar relacionado com o evento da dormência que é uma característica de agressividade inerente às plantas daninhas, porém os tratamentos químicos ainda proporcionaram uma redução pronunciada da germinação, dependendo da dose avaliada (Tabela 6).

A germinação das sementes de R. raphanistrum quando da aplicado isolada do herbicida glyphosate apresentou uma redução significativa de germinação apenas na maior dose do herbicida testado. Silva et al. (2012) ao trabalharem com a cultura do feijão, observaram que a aplicação de sub-doses de glyphosate reduziu a germinação de sementes de feijão. Já o herbicida 2,4-D proporcionou um decréscimo na germinação das sementes com a aplicação das duas doses maiores (670 e 1.005 g ha $\left.{ }^{-1}\right)$. Yamashita, Borges e Carvalho (2010) observaram a germinação sementes de corda-de-viola (Ipomoea quamoclit) em substratos umedecidos por herbicida 2,4-D (670 $\left.\mathrm{g} \mathrm{ha}^{-1}\right)$, neste caso, não houve germinação das sementes de I. quamoclit, tendo esta apenas ocorrido na testemunha.

Quando os herbicidas foram aplicados em mistura observou-se uma redução na germinação das sementes em todos os tratamentos testados. Ressalta-se que, a mistura com as menores doses de glyphosate e 2,4-D $\left(360+335 \mathrm{~g} \mathrm{ha}^{-1}\right)$ na $3^{\mathrm{a}}$ época de aplicação apresentou um efeito de sinergismo, que na prática talvez a utilização desta mistura possa ser vantajoso tanto em termos econômico como ambiental.

\section{Conclusão}

O controle das plantas daninhas na $1^{\text {a }}$ época de aplicação foi excelente para todos os tratamentos, enquanto que no início da formação de vagens $\left(2^{\mathrm{a}}\right.$ época) o controle foi satisfatório, contudo, na $3^{\mathrm{a}}$ época os herbicidas não apresentaram controle eficiente.

A massa seca foi reduzida pela aplicação do herbicida glyphosate exceto pela menor dose do

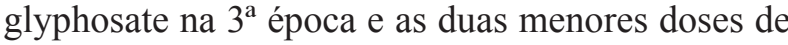
glyphosate+2,4-D. 
A germinação foi alterada negativamente pelos herbicidas nas três épocas de aplicação.

O glyphosate e o 2,4-D aplicados em pósemergência tardia podem além de controlar as plantas daninhas satisfatoriamente, quando na época correta, diminuir a germinação de um possível escape na área reduzindo o banco de sementes da planta daninha.

\section{Referências}

AGOSTINETTO, D.; TIRONE, S. P.; GALON, L.; MAGRO, T. D. Desempenho de formulações e doses de glyphosate em soja transgênica. Revista Trópica Ciências Agrárias e Biológicas, São Luís, v. 3, n. 2, p. 36, 2009.

BOHM, G. M. B.; SCHENEIDER, L.; CASTILHOS, D.; AGOSTINETTO, D.; ROMBALDI, C. V. Controle de plantas daninhas, biomassa e metabolism microbiano do solo em função da aplicação de glifosato ou imazetapir na cultura da soja. Semina: Ciências Agrárias, Londrina, v. 32, n. 3, p. 919-930, jul./set. 2011.

BRASIL. Ministério da Agricultura e Reforma Agrária. Secretaria Nacional de Defesa Agropecuária. Departamento Nacional de Defesa Vegetal. Coordenação de Laboratório Vegetal. Regras para análise de sementes. Brasília, DF, 1992. 365 p.

CARBONARI, C.; MESCHEDE, D. K.; VELINE, E. D. Efeitos da aplicação de glyphosate no crescimento inicial de mudas de eucalipto submetidas a dois níveis de adubação fosfatada. In: SIMPÓSIO INTERNACIONAL SOBRE GLYPHOSATE, 68., 2007, Botucatu. Anais... Botucatu: FEPAF, 2007, p. 68-70.

CASSANEGO, M. B. B.; DROSTE, A.; WINDISCHI, P. G. Effects of 2,4-D on the germination of megaspores and initial development of Regnellidium diphyllum Lindman (Monilophyta, Marsileaceae). Brazilian Journal of Biology, São Carlos, v. 2, n. 4, p. 1-11, 2010.

EMPRESA BRASILEIRA DE PESQUISA AGROPECUÁRIA - EMBRAPA SOJA. As plantas daninhas e a semeadura direta. Londrina, 2001. 59 p. (Embrapa Soja, Circular técnica, 33).

. Centro Nacional de Pesquisa de Solos. Sistema brasileiro de classificação de solos. Brasília: Embrapa Produção de Informação; Rio de Janeiro: Embrapa Solos, 2006. 306 p.
FARINELLI, R.; PENAROL, F. G.; LEMOS, L. B. Eficiência do herbicida 2,4-D no controle de Raphanus sativus L., em pós-emergência na cultura de milheto. Revista Brasileira de Milho e Sorgo, Sete Lagoas, v. 4, n. 1, p. 104-111, 2005.

GODOY, M. C. Efeitos do glyphosate sobre o crescimento e absorção de fósforo pela soja. 2007. Dissertação (Mestrado em Agronomia) - Universidade Estadual Paulista. Faculdade de Ciências Agrárias, Botucatu.

LANDERS, J. N. Curso de plantio direto: histórico, características e benefícios do plantio direto. Módulo 1. Brasília: ABEAS, Universidade de Brasília, 2005. 113 p. (Especialização à Distância).

LIMA, J. D.; ALDRIGHI, M.; SAKAI, R. K.; SOLIMAN, E. P.; MORAES, W. S. Comportamento do nabo forrageiro (Raphanus sativus L.) e da nabiça (Raphanus raphanistrum L.) como adubo verde. Pesquisa Agropecuária Tropical, Goiânia, v. 37, n. 1, p. 60-63, mar. 2007.

LORENZI, H. Manual de identificação e controle de plantas daninhas: plantio direto e convencional. 6. ed. São Paulo: Instituto Plantarum, 2006. 339 p.

MELHORANÇA FILHO, A. L.; PEREIRA, M. R. R.; MARTINS, D. Efeito de subdoses de glyphosate sobre a germinação de sementes das cultivares de soja RR e convencional. Bioscience Journal, Uberlândia, v. 27, n. 5, p. 686-691, set./out. 2011.

OLIVEIRA JÚNIOR, R. S. Mecanismo de ação de herbicidas. In: OLIVEIRA JÚNIOR, R. S.; CONSTANTIN, J.; INOUE, M. H. (Coord.). Biologia e manejo de plantas daninhas. Curitiba: Omnipax, 2011. p. 141-192.

OLIVEIRA JÚNIOR, R. S.; CONSTANTIN, J. Plantas daninhas e seu manejo. 2. ed. Guaíba: Editora Agropecuária, 2001. 364 p.

OLIVEIRA JÚNIOR, R. S.; CONSTANTIN, J.; COSTA, J. M.; CAVALIERI, S. D.; ARANTES, J. G. Z.; ALONSO, D. G.; ROSO, A. C. Interação entre sistemas de manejo e controle de plantas daninhas em pós-emergência afetando o desenvolvimento e a produtividade da soja. Planta Daninha, Viçosa, MG, v. 24, n. 4, p. 721-732, 2006.

PENCKOWSKI, L. H.; PODOLAN, M. J.; LÓPEZOVEJERO, R. F. Influência das condições climáticas no momento da aplicação de herbicidas pós-emergentes sobre a eficácia de controle de nabiça (Raphanus raphanistrum) na cultura do trigo. Planta Daninha, Viçosa, MG, v. 21, n. 3, p. 435-442, 2003.

PITELLI, R. A. Interferência de plantas daninhas em culturas agrícolas. Informativo Agropecuário, Belo Horizonte, v. 11, n. 129, p. 19-27, 1985. 
REEVES, T. G.; CODE, G. R.; PIGGIN, C. M. Seed production and longevity, seasonal emergence, and phenology of wild radish (Raphanus raphanistrum L.). Australian Journal of Experimental and Agriculture Animal Husbandry, v. 21, p. 524-530, 1981.

RODRIGUES, B. N.; ALMEIDA, F. S. Guia de herbicidas. 4. ed. Londrina: IAPAR, 1998. 648 p.

SILVA, R. G. P. O.; SILVA, J. E. N.; MELHRORANÇA FILHO, A. L.; SILVA, C. F. C.; BEZERRA, J. L. S. Efeito de subdoses de glifosate sobre germinação e desenvolvimento inicial do feijoeiro. Enciclopédia Biosfera: Centro Cientifico Conhecer, Goiânia, v. 8, n. 14, p. 475-484, 2012.

SOCIEDADE BRASILEIRA DA CIÊNCIA DAS PLANTAS DANINHAS - SBCPD. Procedimentos para instalação, avaliação e análise de experimentos com herbicidas. Londrina: SBCPD, 1995. 42 p.
VELINI, E. D.; ALVES, E.; GODOY, M. C.; MESCHEDE, D. K.; DUKE, S. O. Glyphosate applied at low doses can stimulate plant growth. Pest Management Science, Londres, v. 64, n. 4, p. 489-496, 2008.

WAGNER, R. M.; KOGAN, A. M. Parada phytotoxic activity of root absorbed glyphosate in corn seedlings (Zea mays L.). Weed Biology and Management, Danvers, v. 3, n. 4, p. 228-232, 2003.

YAMASHITA, O. M.; BORGES, R. H.; CARVALHO, M. A. C. Efeito de três herbicidas na germinação de cordade-viola (Ipomoea quamoclit) em substrato umedecido. Revista Científica Eletrônica de Agronomia, Garça, v. 17, n. 1, p. 17-22, jun. 2010.

YOUNG, K.; COUSENS, R. D. Predicting the emergence of wild radish (Raphanus raphanistrum). Aspects of Applied Biology, n. 51, p. 69-74, 1998. 